\title{
VARIAÇÃO NA QUALIDADE CULINÁRIA DAS RAÍZES DE MANDIOCA $\left({ }^{1}\right)$
}

\author{
JOSÉ OSMAR LORENZI $\left({ }^{2}\right)$
}

\begin{abstract}
RESUMO
A falta de regularidade na qualidade culinária das raízes de mandioca de mesa é um dos fatores de restrição à expansão de seu consumo. Raízes cozidas de boa qualidade, entre outras características, devem apresentar-se, quando esmagadas por um garfo, na forma de uma massa não encaroçada, plástica e não pegajosa. $O$ tempo de cozimento culinário correlaciona-se bem com a qualidade da massa cozida, isto é, quanto menor esse tempo, melhor a massa gerada. Dessa forma, neste trabalho, a duraçāo do tempo de cozimento (DTC) foi usada como método indireto e expedito para avaliação da qualidade culinária das raízes de mandioca. Os fatores que interferem na DTC podem ser reunidos em dois grupos: (a) intrínsecos: variação dentro e entre raízes da mesma planta e entre plantas da mesma variedade; (b) extrínsecos: variação em função do genótipo, do ambiente e do estado fisiológico das plantas. Estudos preliminares realizados pelo Instituto Agronômico (IAC) tiveram por objetivos verificar e quantificar a magnitude dessas variações. Foram desenvolvidos dois experimentos de campo, em dois solos distintos, utilizando cinco variedades amostradas mensalmente, do $7 .^{\circ}$ ao $15 .^{\circ}$ mês de idade das plantas. A DTC foi determinada a partir de água fervente, em subamostras de cada raiz da planta. Os resultados mais relevantes mostraram que: (a) a DTC diminuiu, de 10 a 14 minutos, da base para a ponta da raiz; (b) a amplitude média de variação entre as raízes de uma mesma planta foi de 11,10 e 27 minutos, respectivamente, para plantas com 8,12 e 15 meses; (c) houve diferenças na DTC para variedades (9 minutos) e para tipos de solo (17 minutos); (d) o efeito médio de época de colheita foi de 19 minutos. $\mathrm{O}$ período de menor DTC foi do $7 .^{\circ}$ ao $12 .^{\circ}$ mês de idade das plantas.
\end{abstract}

Termos de indexação: mandioca de mesa, variedades, tempo de cozimento, qualidade culinária.

\section{ABSTRACT \\ CULINARY QUALITY VARIATION IN CASSAVA ROOTS}

Irregular culinary quality of cassava roots has been one of the major point that restricts its expansion for human consumption. A good quality cassava root, after cooking and smashing with a fork, results in a no stick mass, quite plastic and without grooms. Cooking time is closely related to the quality of the cooked mass, i.e., the shorter it takes to cook, the better the mass produced. Therefore,

(1) Trabalho apresentado no "International Meeting on Cassava Flour and Starch", Cali, Colômbia, janeiro de 1994. Recebido para publicação em 1. de março e accito em 8 de novembro de 1994.

$\left({ }^{2}\right)$ Seção de Raízes e Tubérculos, Instituto Agronômico (IAC), Caixa Postal 28, 13001-970 Campinas (SP). 
in this work, the duration of cooking time (DCT) was used as an express method for evaluating culinary quality of cassava roots. Variations in DCT may be related to two group of factors: a) intrinsic - which takes into account within the root variability, root to root, as well as differences among plants of the same variety; b) extrinsic - which considers the effects of plant genotype, environmental conditions and physiological phase of the plant. The main objective of this work is to verify and quantify how DCT was affccted by the described factors. Preliminary studies were performed under field conditions at Instituto Agronômico, Campinas, State of São Paulo, Brazil, using five contrasting cultivars grown up in two different soil types. Root samples were taken monthly from the $7^{\text {th }}$ to the $15^{\text {th }}$ month after planting. DCT was determined with sub-samples of each root of the plant and starting of cooking time was considered at the moment in which roots were immersed in the boiling water. Results indicate that: a) average DCT decreased $12 \mathrm{~min}$ from the base to the tip of the root; b) within the same plant, DTC varied from 11, 10 and 27 min at the age of 8,12 and 15 months respectively; c) difference among cultivars harvested with the age of 7-15 months was 9 min and when soil type was included in the analyses it reached $17 \mathrm{~min}$; d) lowest DCT was observed for harvestings between 7-12 months after planting.

Index terms: sweet cassava, varieties, cooking time, culinary quality.

\section{INTRODUÇÃ̃O}

Na maioria dos países do mundo tropical, nas últimas décadas, ocorreu forte êxodo das populações da zona rural para a urbana. Esse fenômeno provocou muitas mudanças, especialmente nos hábitos alimentares daqueles que migraram para as cidades, em virtude de se defrontarem com nova sistemática de distribuição e comercialização de alimentos. Os mercados organizados dos grandes centros urbanos oferecem grande variabilidade de produtos alimentícios que competem entre si por preço e qualidade. Dessa forma, os consumidores passaram a ser mais exigentes em função das inúmeras opções disponíveis para satisfação de suas necessidades.

A mandioca, na zona rural, sempre foi uma opção alimentar interessante porque, entre outros fatores, grande parte dos consumidores eram também produtores ou podiam obtê-la junto a fornecedores conhecidos, com maior confiabilidade quanto à qualidade do produto.

A instabilidade na qualidade culinária, conhecida tanto por produtores quanto por consumidores, tinha soluções próprias e simples (abstenção, mudança de fornecedor, etc.). Nos mercados dos grandes centros, as incertezas quanto à qualidade, geradas pela necessidade de abastecimento contínuo e anonimato do fornecedor, têm afastado o consumidor, impelindo-o a adquirir produtos alternativos. Somente no Estado de São Paulo, a produção de mandioca de mesa caiu de $424.000 \mathrm{t}$, em 1969/73, para 91.000 t, em 1983/88 (Instituto de Economia Agrícola, 1973-1989).

É certo, todavia, que a mandioca de mesa tem grande potencial para aumentar sua participação nesses mercados, especialmente pela tradição de seu consumo. Já que seu preço é favorável, a garantia da qualidade e a introdução de métodos mais apropriados de apresentação do produto tornam-se requisitos fundamentais para recuperação de seu espaço.

Infelizmente, a qualidade culinária das raízes de mandioca tem sido pouco estudada e as causas de sua variabilidade e instabilidade são pouco conhecidas (Normanha, 1988; Wheatley, 1991). São muitos os fatores de qualidade que podem ser considerados: os de ordem organoléptica, além de subjetivos, têm maior estabilidade e, por essas razões, 
não requerem avaliações sistemáticas. As variáveis consideradas mais importantes são textura, plasticidade e pegajosidade da massa cozida, porque, de seu comportamento, depende a maioria das receitas culinárias preparadas com mandioca (Pereira et al., 1983, 1985). Todavia, essas características estão associadas à duração do tempo de cozimento (DTC), isto é, quanto menor a DTC, melhor a massa gerada. Vários autores relataram resultados que mostram essa correlação, como: Pereira et al. (1985); Fukuda et al. (1988) e Wheatley \& Gomez (1985).

A simples determinação da DTC pode oferecer indicações seguras quanto à qualidade, dispensando-se a análise de parâmetros que tornariam o processo de avaliação complexo e de alto custo, principalmente quando há necessidade de analisar grande número de amostras. Dessa forma, pela facilidade de sua determinação, a DTC pode ser considerada um método expedito de avaliação indireta da qualidade culinária.

Até o momento, são desconhecidos os detalhes das alterações na composição das raízes que implicam nas variações das qualidades culinárias. No entanto, sabe-se que as condições ambientais, o estado fisiológico das plantas e o genótipo são seus principais determinantes. O trabalho de Wheatley (1991) reúne os principais dados da literatura sobre esse assunto c relata a interação desses fatores.

O presente trabalho tcve por objetivos estudar e quantificar a magnitude da variação da DTC em função da idade das plantas e de variedades cultivadas em dois tipos de solo, bem como as variações dentro e entre raízes da mesma planta e entre plantas da mesma variedade.

\section{MATERIAL E MÉTODOS}

Foram instalados, em 20/8/1986, dois ensaios de campo, no Centro Experimental de Campinas, do IAC, situado a $22^{\circ} 05^{\prime}$ de latitude sul e $47^{\circ} 05^{\prime}$ de longitude oeste, a 669 metros de altitude, e cujo clima, segundo a classificação de Köppen é do tipo Cwa. Um dos experimentos foi implantado em latossolo roxo, eutrófico, A moderado, textura muito argilosa (LR) e, outro, em latossolo vermelho-amarelo, distrófico, A moderado, textura argilosa (LVA). As áreas distavam entre si de, aproximadamente, 700 metros e os experimentos não receberam adubação.

Utilizaram-se as principais variedades de mandioca de mesa do Estado de São Paulo, a saber: IAC Mantiqueira, IAC 14-18, IAC Jaçanã, IAC 59-210 e IAC 576-70.

As parcelas experimentais, distantes $2,0 \mathrm{~m}$ entre si e sem bordaduras laterais, tiveram duas linhas de doze plantas, no espaçamento de $1,0 \times 0,8 \mathrm{~m}$, sendo as manivas, de $20 \mathrm{~cm}$ de comprimento, plantadas horizontalmente em sulcos de $10 \mathrm{~cm}$ de profundidade.

O delineamento estatístico adotado foi de blocos ao acaso, com cinco tratamentos (variedades) e seis repetiçôes, dispostos em parcelas subdivididas para nove épocas de colheita.

Nas amostragens das plantas, colheu-se uma planta por repetição, devidamente separada por outras competitivas. A primeira amostragem foi feita aos sete meses e, as outras, a intervalos regulares de 30 dias até o $150^{\circ}$ mês após o plantio.

Após a coleta, todas as raízes da planta amostrada foram subamostradas, utilizando-se um cilindro com cerca de $70 \mathrm{~g}$ da parte mediana de cada raiz. Em seguida, os cilindros foram descascados e submetidos ao cozimento a partir de água fervente, em cestos imersos numa panela com cerca de 20 1 de água. Cada cesto representou uma planta e a DTC foi medida em cada raiz, utilizando-se de um garfo para determinar o ponto ideal de cozimento, até o limite máximo de 60 minutos. Em cada cozimento, incluíram-se todos os tratamentos da mesma repetição, por época e por experimento, obtendo-se a DTC média estimada, por planta, pela média da DTC de suas raízes.

Foi utilizado para determinação da DTC dentro e entre raízes da mesma planta, bem como entre plantas, somente material da variedade IAC 576-70 do experimento do latossolo vermelho-amarelo. 


\section{RESULTADOS E DISCUSSÃO}

Para maior facilidade de apresentação e melhor visualização dos resultados, os fatores estudados e sua influência na duração do tempo de cozimento (DTC) culinário das raízes foram reunidos em dois grupos, a saber: (a) intrínsecos: os que consideraram as variações dentro e entre as raízes da mesma planta e entre plantas da mesma variedade; (b) extrínseces: aqueles relacionados à variação em função do genótipo, das condições ambientais (tipo de solo) e do estado fisiológico das plantas (idade das plantas/época de colheita).

A DTC foi medida até o limite de 60 minutos, tempo esse já considerado excessivo do ponto de vista culinário (Pereira et al., 1985). As amostras que atingiram o limite de 60 minutos apresentaram-se comumente duras e de aspecto vítreo, não alcançando o ponto de cozimento culinário. A "vitrificação" de raízes cozidas é uma característica cujas causas não são bem conhecidas. Segundo Wheatley (1991), esse fenômeno está associado, em parte, à redução de amido e ao aumento de açúcares provocado por algum estresse na planta.

\subsection{Fatores intrínsecos}

\subsubsection{Variação dentro da raiz}

A polpa da raiz é a porção mais importante da mandioca e a mais utilizada para consumo humano na forma fresca.

Naturalmente, pela própria anatomia e pela atuação dos processos fisiológicos de crescimento, acumulação e mobilização de substâncias na raiz, pode-se inferir que sua composição varia tanto no sentido radial quanto no longitudinal, podendo explicar o comportamento diferencial na qualidade culinária, mais comum e perceptível ao longo da raiz.

Assim, a DTC medida em três partes da raiz (base, meio e ponta) apresentou um gradiente decrescente significativo tanto para plantas com $7 \mathrm{me}$ ses de idade (26, 20 e 16 minutos respectivamente) quanto para plantas com 20 meses de idade (36, 28 e 22 minutos respectivamente). Embora a DTC média para plantas com 20 meses fosse maior do que com 7 meses, a magnitude do gradiente (10 e 14 minutos respectivamente), entre elas, não foi expressiva (Quadro 1).

Esses dados refletem um comportamento específico, sendo provável que o gradiente da DTC na raiz possa apresentar valores de outra ordem, inclusive inversos aos obtidos, em função das variações na composição a que as raízes estão sujeitas.

Quadro 1. Duração do tempo de cozimento culinário, em minutos, em diferentes partes da raiz da variedade IAC 576-70, plantada em latossolo vermelho-amarelo, distrófico, A moderado, textura argilosa. (Média de dez repetições)

Parte da raiz $\frac{\text { Idade da planta (meses) }}{7}$ Média

\begin{tabular}{llcl}
\hline & & & \\
\cline { 2 - 4 } Base & 26 & 36 & 31 \\
Meio & 20 & 28 & 24 \\
Ponta & 16 & 22 & 19 \\
\hline Média & 21 & 29 & -- \\
\hline
\end{tabular}

\subsubsection{Variação entre raízes da mesma planta}

No quadro 2, encontram-se os dados obtidos da DTC entre as raízes da mesma planta, colhida aos 8,12 e 15 meses de idade.

Pela sua análise, observa-se que, em apenas uma planta, a DTC não variou entre as raízes. A amplitude média de variação foi de 11,10 e 17 minutos para plantas com 8,12 e 15 meses respectivamente. As diferenças na DTC entre as raízes da mesma planta sugerem que elas possam ser devidas a diferenças na sua composição. Lorenzi et al. (1978) encontraram grandes variações no teor de matéria seca, amido, carboidratos solúveis totais e açúcares redutores, em função do tipo ou origem da raiz na planta, aos 17 dias após a poda da parte aérea. A poda pode ser considerada um fator estressante drástico, capaz de provocar grandes alterações nas 
Quadro 2. Duração do tempo de cozimento culinário, em minutos, entre raízes e entre plantas, em três épocas de colheita, da variedade IAC 576-70, plantada em latossolo vermelho-amarelo, distrófico, A moderado, textura argilosa

\begin{tabular}{|c|c|c|c|c|c|c|}
\hline \multirow{2}{*}{ Plantas } & \multicolumn{2}{|c|}{8 meses } & \multicolumn{2}{|c|}{12 meses } & \multicolumn{2}{|c|}{15 meses } \\
\hline & $\begin{array}{l}\mathrm{N} .^{\circ} \mathrm{de} \\
\text { raízes }\left({ }^{1}\right)\end{array}$ & \multirow{2}{*}{$\begin{array}{c}\begin{array}{c}\text { Tempo de } \\
\text { cozimento }\end{array} \\
\min \end{array}$} & $\begin{array}{l}\mathrm{N} .{ }^{\circ} \mathrm{de} \\
\text { raízes }\left({ }^{1}\right)\end{array}$ & \multirow{2}{*}{$\frac{\begin{array}{l}\text { Tempo de } \\
\text { cozimento }\end{array}}{\min }$} & $\begin{array}{l}\mathrm{N} .^{\circ} \mathrm{de} \\
\text { raízes }\left({ }^{1}\right)\end{array}$ & \multirow{2}{*}{$\begin{array}{c}\begin{array}{c}\text { Tempo de } \\
\text { cozimento }\end{array} \\
\min \end{array}$} \\
\hline & & & & & & \\
\hline & (3) & 18 & (1) & 29 & (2) & 32 \\
\hline \multirow[t]{2}{*}{1} & $5(1)$ & 26 & $4(1)$ & 38 & $8(1)$ & 46 \\
\hline & (1) & 27 & (2) & 50 & (5) & 60 \\
\hline \multirow[t]{2}{*}{ Média } & & 21 & & 42 & & 51 \\
\hline & (1) & 16 & (6) & 23 & (3) & 35 \\
\hline \multirow[t]{3}{*}{2} & $9(3)$ & 21 & $10(2)$ & 31 & $7(1)$ & 51 \\
\hline & (3) & 25 & (1) & 32 & (1) & 59 \\
\hline & (2) & 26 & (1) & 35 & (2) & 60 \\
\hline Média & & 23 & & 27 & & 48 \\
\hline \multirow[t]{2}{*}{3} & $7(6)$ & 19 & $5(4)$ & 25 & $4(3)$ & 28 \\
\hline & (1) & 26 & (1) & 27 & (1) & 48 \\
\hline \multirow[t]{3}{*}{ Média } & & 20 & & 25 & & 33 \\
\hline & (1) & 21 & (4) & 27 & (1) & 34 \\
\hline & (1) & 23 & (2) & 28 & (1) & 55 \\
\hline \multirow[t]{3}{*}{4} & $8(3)$ & 32 & $10(2)$ & 35 & 7 (1) & 58 \\
\hline & (1) & 34 & (1) & 37 & (4) & 60 \\
\hline & (2) & 40 & (1) & 38 & & \\
\hline Média & & 32 & & 31 & & 55 \\
\hline \multirow[t]{2}{*}{5} & $4(3)$ & 25 & $8(3)$ & 22 & $3(1)$ & 25 \\
\hline & (1) & 29 & (5) & 25 & (2) & 60 \\
\hline \multirow[t]{2}{*}{ Média } & & 26 & & 24 & & 48 \\
\hline & (1) & 23 & $7(7)$ & 26 & (2) & 35 \\
\hline \multirow[t]{3}{*}{6} & $6(4)$ & 27 & & & $6(2)$ & 40 \\
\hline & (1) & 38 & & & (1) & 51 \\
\hline & & & & & (1) & 60 \\
\hline Média & & 28 & & 26 & & 44 \\
\hline \multicolumn{2}{|c|}{ Média/planta } & 25 & & 29 & & 47 \\
\hline \multicolumn{7}{|c|}{ Amplitude máxima de } \\
\hline \multirow{2}{*}{\multicolumn{2}{|c|}{$\begin{array}{l}\text { variação entre plantas } \\
\text { Amplitude média de } \\
\text { variação entre raízes }\end{array}$}} & 12 & & 18 & & 22 \\
\hline & & 11 & & 10 & & 27 \\
\hline
\end{tabular}

(1) Valores entre parênteses referem-se ao número de raizes subdivididas de acordo com o tempo de cozimento culinário. 
raízes; todavia, esses autores não descartam a possibilidade de tais variações ocorrerem também em função de outros fatores e alertam sobre os critérios de amostragem para análises.

As diferenças maiores encontradas em plantas com 15 meses, em relação a 8 e 12 meses, podem ser explicadas pelo próprio efeito da idade e/ou época de colheita, associada a maior número de variáveis ambientais, na composição das raízes.

\subsubsection{Variação entre plantas da mesma variedade}

A propagação vegetativa da mandioca garante a uniformidade genética da variedade; portanto, as variações existentes entre plantas resultam da ação de outros fatores, bióticos e/ou abióticos.

As médias da DTC, por planta - Quadro 2 mostram a magnitude dessas variações atribuídas a tais fatores. Aos 8,12 e 15 meses, as médias foram, respectivamente, de 25,29 e 47 minutos, enquanto as amplitudes de suas variações foram de 12,18 e 22 minutos. Os incrementos na DTC e a correlação observada entre esses valores pode ser explicada em função da ação do maior número desses fatores, no tempo, e conseqüente ampliação da heterogeneidade das plantas. Mesmo que a principal fonte das variações seja devida a fatores externos, há, todavia, fatores intrínsecos, como o material de plantio, que podem condicionar desen- volvimento diferenciado entre as plantas, com possíveis reflexos na sua qualidade culinária.

\subsection{Fatores extrínsecos}

\subsubsection{Efeito da variedade}

O efeito da variedade na DTC foi altamente significativo. A média do somatório de todas as épocas de colheita mostrou que a 'IAC 576-70' teve a menor DTC para os dois tipos de solo, embora não tenha diferido estatisticamente da 'IAC Jaçanã' no LVA (Quadros 3 e 4). As interações variedade $x$ época de colheita e variedade $\mathrm{x}$ tipo de solo parecem não ser significativas, apesar de os dados não terem sido submetidos à análise da variância. As diferenças médias varietais, todavia, foram menores no LVA (7 minutos) do que no LR (12 minutos), expressando uma variação total média de 9 minutos devido ao fator genético.

Embora o efeito de variedade na DTC não tenha alcançado a mesma expressão que os outros fatores, é de grande importância prática, uma vez que é o de mais fácil manejo. A supcrioridade da 'IAC 576-70', nesse aspecto, também foi encontrada em outros trabalhos, relatados por Vilella et al. (1985) e Lorenzi et al. (1990). Essa característica, associada a outras de interesse agronômico e culinário, faz da 'IAC 576-70' a principal variedade de mesa atualmente cultivada no Estado de São Paulo.

Quadro 3. Duração do tempo de cozimento culinário, em minutos, de variedades de mandioca cultivadas em latossolo roxo, em função da idade das plantas

\begin{tabular}{|c|c|c|c|c|c|c|c|c|c|c|}
\hline \multirow{2}{*}{ Variedades } & \multicolumn{9}{|c|}{ Idade das plantas (meses) } & \multirow{2}{*}{ Média $\left({ }^{l}\right)$} \\
\hline & 7 & 8 & 9 & 10 & 11 & 12 & 13 & 14 & 15 & \\
\hline IAC Mantiqueira & 55 & 48 & 52 & 58 & 57 & 58 & 59 & 60 & 60 & $56 \mathrm{c}$ \\
\hline IAC $14-18$ & 60 & 52 & 48 & 53 & 54 & 57 & 59 & 60 & 60 & $56 \mathrm{c}$ \\
\hline IAC Jaçanã & 51 & 46 & 41 & 46 & 48 & 48 & 56 & 58 & 59 & $50 \mathrm{~b}$ \\
\hline IAC $59-210$ & 60 & 54 & 56 & 49 & 56 & 60 & 60 & 60 & 60 & $57 \mathrm{c}$ \\
\hline IAC $576-70$ & 36 & 37 & 34 & 43 & 40 & 45 & 54 & 58 & 58 & $45 \mathrm{a}$ \\
\hline Média & 52 & 47 & 46 & 50 & 51 & 54 & 58 & 59 & 59 & 53 \\
\hline
\end{tabular}

( $\left.{ }^{1}\right)$ Médias seguidas por letras distintas diferem entre si pelo teste de Tukey a $5 \%$. 
O efeito varietal na DTC já era bem conhecido e a magnitude de sua variação foi similar à encontrada por Pereira et al. (1985) e Fukuda et al. (1988).

\subsubsection{Efeito do tipo de solo}

O tipo de solo exerceu influência altamente significativa na DTC das raízes (Quadros 5 e 6).

Todas as variedades, em todas as épocas, apresentaram menor DTC no LVA em relação ao LR, sendo a amplitude média de variação de 17 minutos.

Apesar da pequena distância entre as duas áreas experimentais, suas características são bem contrastantes. O LR, pelo seu caráter eutrófico, tem mais bases trocáveis (Ca e $\mathrm{Mg}$ principalmente) e ocupa a parte mais alta do relevo, enquanto o LVA, distrófico, mais pobre em bases, porém mais rico em $\mathrm{K}$ e $\mathrm{P}$, pela situação na parte mais baixa do relevo, condiciona maior disponibilidade de água e matéria orgânica. Como as condições macroclimáticas são semelhantes nas duas áreas, a maior produtividade de raízes e a menor DTC no LVA indicam que esses fatores podem estar associados e que dependem, em grande parte, de um conjunto de características do solo, oferecendo condições mais favoráveis ao desenvolvimento das plantas. Estas, assim, estariam menos sujeitas a estresses dessa natureza, os quais provocariam possíveis alterações na composição ou em alguns componentes das raízes diretamente relacionados à DTC. Variação na qualidade por estresse foi discutida por Wheatley (1991) e pode explicar, em grande parte, os resultados deste trabalho.

Efeitos da fertilidade do solo e da adubação potássica na qualidade das raízes foram encontrados por Ashokan \& Sreedharan (1977), CIAT (1984) e Lorenzi et al. (1990).

\subsubsection{Efeito da idade das plantas}

Os dados apresentados sobre o efeito da idade das plantas na DTC estão confundidos com o de época de colheita. Não se encontraram trabalhos na literatura mostrando o efeito da idade, exclusivamente, na qualidade culinária; todavia, segundo Wheatley (1991), há indicações de que ele possa ser menor do que o efeito de época.

A mandioca é uma cultura de ciclo longo e não tem época definida de maturação. Há períodos, entretanto, especialmente entre o final do primeiro e o início do segundo ciclo vegetativo, de maior estabilidade na produção e na composição das raízes, os quais, normalmente, coincidem com as melhores épocas de colheita do ponto de vista culinário. Os resultados mostraram que, apesar de pequenas variações, esse período foi do $7 .^{\circ}$ ao $12 .^{\circ}$ mês de idade das plantas (março a agosto), evidenciado pela menor DTC das raízes (Quadro 5). A partir do $13 .^{\circ}$, a DTC aumentou e, conseqüentemente, a qualidade culinária das raízes piorou e tornou-se mais heterogênea.

Quadro 4. Duração do tempo de cozimento culinário, em minutos, de variedades de mandioca cultivadas em latossolo vermelho-amarelo, em função da idade das plantas

\begin{tabular}{lcccccccccc} 
& \multicolumn{8}{c}{ Idade das plantas (meses) } & Média (1) \\
\cline { 2 - 8 } Variedades & 7 & 8 & 9 & 10 & 11 & 12 & 13 & 14 & 15 & \\
\hline IAC Mantiqueira & 32 & 31 & 26 & 36 & 38 & 35 & 47 & 53 & 55 & $39 \mathrm{c}$ \\
IAC 14-18 & 29 & 31 & 26 & 35 & 39 & 34 & 41 & 45 & 53 & $37 \mathrm{bc}$ \\
IAC Jaçanã & 25 & 31 & 26 & 29 & 37 & 31 & 38 & 37 & 51 & $34 \mathrm{ab}$ \\
IAC 59-210 & 41 & 38 & 29 & 32 & 39 & 34 & 44 & 45 & 53 & $39 \mathrm{c}$ \\
IAC 576-70 & 24 & 25 & 23 & 27 & 30 & 29 & 37 & 47 & 44 & $32 \mathrm{a}$ \\
\hline Média & 30 & 31 & 26 & 32 & 37 & 33 & 42 & 45 & 51 & 36 \\
\hline
\end{tabular}

(1) Médias seguidas por letras distintas diferem entre si pelo teste de Tukey a $5 \%$. 
Quadro 5. Duração do tempo médio de cozimento culinário (minutos) e produção média (t/ha) de raízes de cinco variedades de mandioca em função da idade das plantas e do tipo de solo

\begin{tabular}{|c|c|c|c|c|c|c|c|c|c|c|c|}
\hline \multirow{2}{*}{ Tipo de solo } & & \multicolumn{9}{|c|}{ Idade das plantas (meses) } & \multirow{2}{*}{ Média( $\left.{ }^{1}\right)$} \\
\hline & & 7 & 8 & 9 & 10 & 11 & 12 & 13 & 14 & 15 & \\
\hline \multirow[b]{2}{*}{ LR } & Minutos & 52 & 47 & 46 & 50 & 51 & 54 & 58 & 59 & 59 & $53 \mathrm{~b}$ \\
\hline & t/ha & 5,5 & 6,8 & 8.7 & 10,8 & 12,4 & 11.8 & 9,7 & 12,4 & 13,1 & 10,1 \\
\hline \multirow[b]{2}{*}{ LVA } & Minutos & 30 & 31 & 26 & 32 & 37 & 33 & 42 & 45 & 51 & $36 \mathrm{a}$ \\
\hline & t/ha & 12,4 & 19,5 & 18,8 & 23,2 & 26,1 & 24,1 & 24,0 & 25,1 & 27,0 & 22,3 \\
\hline \multirow{2}{*}{ Média $\left({ }^{1}\right)$} & Minutos & $41 b$ & $39 b$ & $36 \mathrm{a}$ & $41 \mathrm{~b}$ & $44 \mathrm{c}$ & $44 c$ & $50 \mathrm{~d}$ & $52 \mathrm{~d}$ & $55 \mathrm{e}$ & 45 \\
\hline & t/ha & 9,0 & 13,2 & 13,8 & 17,0 & 19,3 & 18,0 & 16,9 & 18,8 & 20,1 & 16,2 \\
\hline
\end{tabular}

(1) Médias seguidas por letras distintas diferem entre si pelo teste de Tukey a $5 \%$.

Quadro 6. Duração do tempo de cozimento culinário das raízes, em minutos, de variedades de mandioca em função do tipo de solo $\left({ }^{1}\right)$

\begin{tabular}{lll}
\hline \multirow{2}{*}{ Varicdades } & \multicolumn{2}{c}{ Tipo de solo } \\
\cline { 2 - 3 } LR Média
\end{tabular}
minutos

\begin{tabular}{llll} 
IAC Mantiqueira & 56 & 39 & $48 \mathrm{c}$ \\
IAC 14-18 & 56 & 37 & $47 \mathrm{c}$ \\
IAC Jaçanã & 50 & 34 & $42 \mathrm{~b}$ \\
IAC 59-210 & 57 & 39 & $48 \mathrm{c}$ \\
IAC 576-70 & 45 & 32 & $39 \mathrm{a}$ \\
\hline Média & $53 \mathrm{~b}$ & $36 \mathrm{a}$ & 45
\end{tabular}

( ${ }^{1}$ ) Médias de cozimentos mensais do $7 .^{\circ}$ ao $15 .^{\circ}$ mês de idade das plantas.

Os dados obtidos revelaram também que esse fator, entre os estudados, apresentou a maior magnitude de variação da DTC (média de 19 minutos). Isso já era esperado, mesmo porque o longo período de exposição das plantas a grande número de variáveis ambientais, sobretudo climáticas, provoca variações no metabolismo, alterando a amplitude dos componentes da raiz e/ou das propriedades de alguns componentes, em especial, do amido. Wheatley \& Gomez (1985) também verificaram aumento no tempo de cozimento e piora na qualidade culinária das raízes, em função da idade crescente das plantas.

\section{CONCLUSÕES}

A duração do tempo de cozimento (DTC) variou dentro e entre raízes da mesma planta e entre plantas da mesma variedade. Variou, também, em função da variedade, do tipo de solo e das épocas de colheita consideradas, na seguinte conformidade:

1. A DTC foi decrescente da base para a ponta da raiz. A amplitude desse gradiente foi de 10 a 14 minutos, para plantas com 7 e 20 meses de idade respectivamente.

2. A amplitude média de variação da DTC entre raízes foi de 11,10 e 27 minutos, para plantas com 8,12 e 15 meses de idade respectivamente.

3. A amplitude máxima de variação da DTC entre plantas da variedade IAC 576-70 foi de 12,18 e 22 minutos para plantas com 8,12 e 15 meses de idade respectivamente. 
4. A variação média devida ao genótipo foi de 9 minutos. A 'IAC 576-70' apresentou a menor D'TC.

5. O tipo de solo foi responsável por uma variação na DTC de 17 minutos: aquele considerado de maior fertilidade apresentou menor DTC.

6. A amplitude média de variação da DTC em vista da época de colheita foi de 19 minutos, sendo o período de menor DTC do $7 .^{\circ}$ ao $12 .^{\circ}$ mês de idade das plantas.

\section{REFERÊNCIAS BIBLIOGRÁFICAS}

ASHOKAN, P.K. \& SREEDHARAN, C. Influence of levels and time of application of potash on growth and quality of tapioca. Journal of Root Crops, Trivandrum, 3(2):1-4, 1977.

CENTRO INTERNACIONAL DE AGRICULTURA TROPICAL. Cassava program annual report for 1982 and 1983. Cali, CIAT, 1984. 251p.

FUKUDA, W.M.G. \& BORGES, M. de F. Avaliação qualitativa de cultivares de mandioca de mesa. Revista Brasileira de Mandioca, Cruz das Almas, 7(1):63-71, 1988.

INFORMAÇÕES ECONÔMICAS. São Paulo, Instituto de Economia Agrícola, 1973-1989.

LORENZI, J.O.; GUTIERREZ, L.E.; NORMANHA, E.S. \& CIONE, J. Variação de carboidratos e ácido cianídrico em raízes de mandioca, após a poda da parte aérea. Bragantia, Campinas, 37:139-144, 1978.
LORENZI, J.O.; MONTEIRO, D.A.; CARVALHO, A.P. de; ASSIS, C.M. de O.A.; DEAK, L.G. \& IGUE, T. Testes regionais de variedades de mandioca de mesa no Estado de São Paulo. Bragantia, Campinas, 49(2):391-401, 1990.

NORMANHA, E.S. O mau cozimento dos aipins: uma hipótese. O Agronômico, Campinas, 40(1):13-14, 1988.

PEREIRA, A.S.; LORENZI, J.O.; KLATILOVA, E.; PERIM, S.; COSTA, I.R.S.; PENNA, S.; VALLE, T.L. \& FRANÇA, J.P.M. de. A mandioca na cozinha brasileira. Campinas, Instituto Agronômico, 1983. 266p. (Boletim, 213)

PEREIRA, A.S.; LORENZI, J.O. \& VALLE, T.L. Avaliação do tempo de cozimento e padrão de massa cozida em mandiocas de mesa. Revista Brasileira de Mandioca, Cruz das Almas, 4(1):27-32, 1985.

VILELLA, O.V.; PEREIRA, A.S.; LORENZI, J.O.; VALLE, T.L.; MONTEIRO, D.A.; RAMOS, M.T.B. \& CEMBRANELLI, N.S. Competição de clones de mandioca (Manihot esculenta Crantz) selecionados para mesa e indústria. Bragantia, Campinas, 44(2):559-568, 1985.

WHEATLEY, C.C. Calidad de las raices de yuca y factores que intervienen en ella. In: HERSHEY, C.H., ed. Mejoramiento genético de la yuca en América Latina, Cali, CIAT, 1991. p.267-291.

WHEATLEY, C.C. \& GOMEZ, G.G. Evaluation of some quality characteristics in cassava storage roots. Qualitas Plantarum Plant Foods for Human Nutrition, S' Gravenhage, 35:121-129, 1985. 